\title{
Antirracismo, ações afırmativas e pré-vestibulares populares
}

Andreia Clapp Salvador ${ }^{1}$

Ana Paula Procopio da Silva²

Jussara Francisca de Assis dos Santos ${ }^{3}$

A sociedade brasileira é estruturalmente constituída pela desigualdade social e tem como sua base de fundação o racismo. Um atributo estrutural de sua formação social e histórica que articula ainda os marcadores de classe, gênero e sexualidade e que na atualidade restringe o acesso da população negra, pobre, indígena, mulheres e LGBTQIA+ aos direitos sociais básicos de saúde, educação, cultura, trabalho e habitação, dentre outros. Nesse sentido, um dos maiores desafios do Brasil contemporâneo é o enfrentamento racializado das desigualdades sociais, ou seja, o antirracismo como um princípio básico da proteção social e determinante para a equidade do acesso aos direitos sociais.

Os dados indicativos das iniquidades raciais fundamentam a compreensão acerca da profundidade da questão racial no país. No tocante ao acesso à renda e à educação, o Relatório das desigualdades de raça, gênero e classe do GEEMA, com base em dados da PNAD de 2011 a 2015, constatou que 19\% da população branca concluiu o ensino superior, enquanto entre pretos e pardos esse percentual é de 7\%. A média de anos de estudo entre brancos é de 10 anos e da população preta e parda é de 8 anos; a renda familiar per capita dos brancos foi $80 \%$ superior à de pretos e pardos no período. Os brancos são super-representados nas ocupações intelectuais enquanto os pretos e pardos são super-representados no trabalho manual, demonstrando a concentração da divisão racial da educação e do trabalho ${ }^{4}$.

Os dados são recentes, mas as reivindicações negras por direitos não são uma novidade no país. Instituições como a Frente Negra Brasileira, fundada em 1931, e o Teatro Experimental do Negro, criado em 
1944, já denunciavam o racismo e demandavam do Estado políticas que promovessem a igualdade de oportunidades para as populações negras. Contudo, o marco de engajamento institucional do Estado brasileiro com a questão racial é o ano de 1995, quando os movimentos negros realizaram no 20 de novembro, em Brasília, a Marcha Zumbi dos Palmares contra o Racismo, pela Cidadania e pela Vida. A Marcha que contou com a presença de mais de trinta mil participantes encaminhou ao governo federal o documento "Programa de Superação do Racismo e da Desigualdade Racial" exigindo a implementação de políticas públicas valorativas e afırmativas. Tem origem nessa mobilização a movimentação do Estado brasileiro para a construção do arcabouço legal que fundamentou a igualdade racial como política pública.

Nos anos 2000, as estratégias de combate às desigualdades raciais passaram a figurar como Política Nacional de Igualdade Racial - PNPIR, com o "objetivo principal de reduzir as desigualdades raciais no Brasil, com ênfase na população negra". As políticas de ação afirmativa, voltadas para a alteração dos quadros de desigualdade social, são, segundo o Ministro Joaquim Barbosa (2003), políticas públicas ou privadas que buscam a efetivação da igualdade de oportunidade, logram maior diversidade e maior representatividade de grupos sociais que vivem em condições desiguais e propõem uma maior inclusão social. A ação das ações afırmativas ainda é pouco reconhecida no campo do que o Ministro e jurista chama de "efeitos persistentes", de ordem cultural, pedagógica e psicológica, que se originaram no passado e que ainda se mantêm. Assim, a implementação de políticas afırmativas provocaria alterações na esfera da igualdade e no campo da consciência social, pautada na perspectiva de reconhecimento das diferenças e como estratégia de enfrentamento das desigualdades fundadas nas iniquidades raciais.

O Movimento Negro-MN, no conjunto da sua diversidade, ao longo da sua história, atuou em diversas frentes voltadas para a denúncia e o arrefecimento das desigualdades raciais e tem desempenhado um 
papel fundante no campo das políticas afirmativas, seja na esfera da luta e reivindicação, como também, como elemento educador. Nilma Lino (2018) afırma o caráter emancipatório, reivindicativo e afırmativo do Movimento Negro e destaca duas principais dimensões, como ator político e "como educador de pessoas, coletivos e instituições sociais" (p.23). O caráter reivindicativo, emancipatório, afırmativo e educativo do MN é identificado em diversas frentes e pode ser exemplificado na atuação do Pré-Vestibular para Negros e Carentes (PVNC), um movimento social de educação popular, que na década de 1990, intensificou a luta em prol do acesso de estudantes negras e negros, da classe popular e periféricos às Universidades Brasileiras e passou a exigir a execução de políticas de ação afirmativa. O PVNC criou uma rede de cursinhos populares pré-universitários que atuavam no campo da educação formal, voltada para aprovação no vestibular, como também, no campo da formação crítica, privilegiando o debate do antirracismo e dos direitos humanos. O PVNC constituiu uma rede de cursinhos populares e inspirou a criação de diversos outros pré-vestibulares comunitários.

Os pré-vestibulares populares, também chamados de comunitários ou sociais, vêm formando, ao longo de três décadas, estudantes negras e negros, indígenas, LGBTQIA+ e demais grupos em condição de desigualdade social, para a inserção universitária. Funcionando nas periferias, favelas e em diversas instituições do Rio de Janeiro, têm uma proposta dirigida às classes populares, atuam de forma gratuita e as atividades são ministradas por educadores voluntários. Muitos estudantes dos pré-vestibulares populares ingressam, através de políticas afırmativas de corte racial, étnico e social, em Universidades públicas, privadas e comunitárias, contribuindo assim para uma maior democratização do ensino superior.

As ações afırmativas promovem acesso a meios fundamentais (educação, emprego) para grupos historicamente discriminados. Além desse aspecto, Moehlecke (2002, p. 200) aponta que a ação afırmativa 
ocorre em sociedades democráticas onde o mérito individual e a igualdade de oportunidades são tidos como seus principais valores, como é o caso do Brasil, surgindo a partir do desenvolvimento de uma ordem jurídica que objetiva equilibrar as condições entre os indivíduos.

No que diz respeito à dimensão racial, Ribeiro (2010) argumenta que o Movimento Negro e a organização de mulheres negras brasileiras são referências ao forjarem estratégias para o diálogo com o Estado e a sociedade para o desenvolvimento de políticas de igualdade racial, tendo como mecanismo as ações afırmativas para o atendimento às necessidades históricas da população negra. A autora afırma que um Estado que se diz democrático deve considerar a "incompatibilidade entre racismo e democracia" (p.31).

O momento atual representa um dos períodos de maior desmonte de políticas sociais, sendo as ações afırmativas, especialmente, as cotas raciais para acesso ao ensino superior, alvo de intensos ataques. Sendo assim, há urgência no fortalecimento de reflexões e iniciativas que demonstrem a necessidade das políticas de ação afırmativa como um dos mecanismos de enfrentamento às ofensivas conservadoras, e até mesmo reacionárias, que têm colocado em risco o projeto de igualdade racial que começou a ser empreendido no país. Nessa direção, o artigo que abre o número temático, Comissões de Heteroidentificação Étnico-Racial: lócus de constrangimento ou de controle social de uma política pública? de Sales Augusto dos Santos, nos traz reflexões importantes sobre o controle social na coibição de fraudes no sistema de cotas nas universidades públicas considerando o caráter tanto inovador como transformador dessa política pública. Uma política de promoção de igualdade racial cuja justificativa tem raízes estruturais. Abordagem realizada por Joílson Santana Marques Jr. em Racismo no Brasil e racismo à brasileira: traços originários que demonstra como o racismo, tendo em vista as linhas que o compõe, se caracteriza por uma "forma sofisticada que responde a concretude das relações raciais brasileiras", sendo esse um aspecto fundamental para 
entendermos a complexidade das ações antirracistas na transformação social. Em sequência, a institucionalização das ações afırmativas desde a sua apreensão pelos membros dirigentes do legislativo é o tema do texto, Do movimento negro à escola pública: como as ações afirmativas foram pensadas pelos parlamentares do Congresso Nacional de Luma Doné Miranda.

$\mathrm{Na}$ bloco seguinte são abordadas as experiências empreendidas pela sociedade civil na ampliação do acesso à educação universitária, no artigo Antirracismo no currículo da EDUCAFRO: um movimento negro em direção à universidade, Sara C. de Castilho Dâmaso dos Santos e Amílcar Araújo Pereira, nos trazem uma reflexão sobre a atuação de pré-vestibulares populares, a partir do exemplo da EDUCAFRO, compreendido como um espaço valoroso no enfrentamento das desigualdades sociais e do racismo que as estrutura. A EDUCAFRO é aqui considerada como uma organização do movimento negro que luta por questões raciais e teve participação efetiva em mudanças no espaço universitário com a ampliação da presença de negros e negras. Essa transformação passa tanto pela ocupação de espaços historicamente negados à população negra, quanto pela formação de subjetividades. Em prosseguimento, Jorge Augusto Correa Ribeiro no texto Cursos Pré-Vestibulares Comunitários: o caso do IFHEP e sua contribuição para o combate do racismo, discute como os pré-vestibulares sociais podem contribuir para a formação política e tomada de consciência de jovens negros acerca do racismo, ressaltando o importante papel exercido por pré-vestibulares sociais, de origem popular e de cunho antirracista no que se refere à luta por políticas de ações afırmativas na universidades brasileiras. E fechando a sequência, Humberto Salustriano da Silva e Francisco Overlande Manço de Souza nos apresentam A Experiência de Jovens Estudantes do Pré- Vestibular Comunitário do Centro de Estudos e Ações Solidárias da Maré (CEASM): Entre as Marcas do Colonialismo e a Pedagogia Decolonial, no qual identificam como tema central para a análise das ex- 
periências tanto as marcas do colonialismo nas trajetórias de jovens periféricos como suas percepções no que se refere às pedagogias críticas decoloniais praticadas no âmbito de uma educação popular.

As vivências de estudantes cotistas, as transformações operadas pela reserva de vagas de corte racial e social nas instituições de ensino e as estratégias contemporâneas de educação antirracista são os temas do bloco subsequente. Educação antirracista nas universidades públicas: novos sujeitos, velhas estruturas e demandas além das cotas, de Maria Raimunda Penha Soares e Rebeca Ribeiro da Silva, problematiza o descompasso entre a crescente inserção de estudantes negras e negros nas universidades públicas e a implementação de uma educação antirracista, destacando o papel de referência dos programas de extensão universitária.

As autoras Ana Paula Souza do Prado Anjos e Marilde Queiroz Guedes, em Política de cotas da UNEB: ação institucional com ressonância nacional destacam a potencialidade das políticas de cotas raciais e sociais em relação à democratização do acesso à educação superior a partir da UNEB identificando o pioneirismo da referida universidade no que diz respeito ao acesso à graduação e a pós-graduação cuja repercussão teve alcance nacional.

No artigo Ações Afirmativas no Vestibular da UERJ: uma análise do perfil socioeconômico dos candidatos as cotas étnico-raciais, Renata da Fonseca Silva Fernandes e Viviane Maurício Figueiredo Machado apresentam uma análise do histórico legislativo do Sistema de Cotas para acesso aos cursos de graduação da UERJ e um estudo sobre o perfil dos candidatos ao Vestibular pelo Sistema de Reserva de Vagas da Universidade do Estado do Rio de Janeiro - UERJ, na opção por cota étnico-racial (2018). A pesquisa evidencia elementos relevantes para o debate das cotas raciais, reafirma a efetividade das políticas públicas de ações afırmativas no campo do ensino superior e indica a necessidade de as Universidades adotarem uma ação proativa no campo das políticas afirmativas. 
Em A política de cotas em um Instituto Superior de Educação: as experiências de estudantes negros cotistas, Luiz Gustavo Borges do Rosario e Josete Pereira Peres Soares destacam uma das ramificações das ações afırmativas, a política de cotas, investigando suas possibilidades como ferramenta de diversidade e justiça social, através da realização de pesquisa com estudantes negras e negros cotistas do curso de pedagogia de um Instituto Superior de Educação, localizado no interior do Estado do Rio de Janeiro.

Em As ações afirmativas na educação e as Narrativas dos Estudantes Negros: desigualdades, protagonismo negro e reparação, Maria Aparecida Miranda apresenta resultados da pesquisa sobre ações afırmativas na Educação Profissional Técnica de Nivel Médio e as narrativas dos estudantes negros de um Instituto Federal de Educação, pressupondo as ações afırmativas como uma reparação histórica de desigualdades e configurando os três eixos das ações afırmativas na educação: acesso através da reserva de vagas ou cotas, educação para as relações étnico-raciais e assistência estudantil, contribuindo para o aprofundamento de reflexões acerca das desigualdades raciais, o protagonismo do Movimento Negro e a emergência das ações afırmativas.

Encerrando as reflexões do bloco, a vivência do antirracismo na educação do ensino básico está presente no artigo Turbantes e bonecas abayomi: estratégias para o fortalecimento da etnicidade afro-brasileira em espaços educativos de Bruna de Paula Pereira e Maria Alice Rezende Gonçalves, em que as autoras descrevem e analisam as ações educativas desenvolvidas por uma blogueira e ativista negra, visando o fortalecimento da etnicidade afro-brasileira em espaços escolares, com oficinas de turbantes e bonecas realizadas em uma escola em Mesquita/RJ. As ofıcinas descritas no artigo são consideradas como ferramentas para o fortalecimento da etnicidade afro-brasileira no espaço escolar. A pesquisa conclui que o ativismo digital possui um potencial educativo na medida em que possibilita a difusão da informação sobre as questões ligadas à valorização e ao fortalecimento da 
identidade negra, bem como a extensão dessas ações no espaço presencial escolar. Desta forma, as ações educativas contribuíram para o estreitamento dos laços entre a escola e a comunidade no processo de implementação da lei n 10.639/03.

Finalizando o dossiê temático, Vanessa Cristina dos Santos Saraiva e Carla Cristina Lima de Almeida, no artigo Direito à Convivência Familiar e Comunitária: o Cadastro Nacional de Adoção sob a mira das lutas antirracistas fazem um estudo acerca do Cadastro Nacional de adoção, considerando-o como um mecanismo de reafirmação de práticas racializadas ao instrumentalizar o quesito cor ou raça na "escolha" do filho de acordo com o ideal da branquitude. O artigo afırma que práticas racializadas estão institucionalizadas em diferentes espaços públicos e privados tendo em vista que, crianças e adolescentes negros, não são escolhidos nos processos de adoção.

Na seção Resenha, Aline Batista de Paula, nos provoca à leitura do belo e necessário livro de Nilma Lino Gomes, O movimento negro educador: saberes construídos nas lutas por emancipação. Porque mais do que nunca precisamos olhar para trás e rever na história as formas de organização, luta e resistência de mulheres e homens negras e negros tanto como forma de reconhecimento pelo seu papel educador, mas também como alento para seguirmos projetando e construindo um futuro de emancipação humana, distribuição equânime das riquezas socialmente produzidas, respeito à diversidade e intercâmbio harmônico e sustentável da humanidade com a natureza.

Desejamos que a leitura instigue novas reflexões e proposições democráticas e antirracistas na educação e em todos os espaços da vida social, principalmente, por nos encontrarmos num cenário nacional em que a pandemia de COVID-19 se arrasta com uma imunização feita à conta-gotas e com mais de 300.000 óbitos, e em que a crise social e sanitária aprofunda ainda mais iniquidades raciais que baseiam as desigualdades sociais no país. 


\section{Referências}

COMES, Joaquim Barbosa. O Debate Constitucional sobre as Ações Afırmativas. In: SANTOS, Renato Emerson dos e LOBATO, Fátima (Orgs). Ações Afirmativas: políticas públicas contra as desigualdades raciais. Rio de Janeiro: DP\&A, 2003.

GOMES, Nilma Lino. O movimento Negro educador - saberes construídos nas lutas por emancipação. Rio de Janeiro: Vozes, 2017.

MOEHLECKE, Sabrina. Ação afırmativa: História e debates no Brasil, Cadernos de Pesquisa. n¹17, 2002.

RIBEIRO, Matilde. Políticas de promoção da igualdade racial no Brasil (19862010). Rio de Janeiro: Garamond, 2014.

\section{Notas}

1 Assistente Social, Doutora em Serviço Social pela PUC-Rio e professora do Departamento de Serviço Social da PUC-Rio, Orcid n 0000-0002-4501-6714, e-mail: aclapp@puc-rio.br.

2 Psicóloga e Assistente Social, Doutora em Serviço Social pela UFRJ e professora da Faculdade de Serviço Social da UERJ, Rio de Janeiro, Orcid nº 0000-00034420-1114, E-mail: ana.procopio@uerj.br

3 Assistente Social, Doutora em Serviço Social pela UFRJ e professora da Escola de Serviço Social da UFF, Niterói, Orcid n 0000-0002-4819-775X, E-mail: jussaraassis@id.uff.br

4 Relatório das Desigualdades de raça, gênero e classe - Crupo de Estudos Multidisciplinares da ação afırmativa GEMAA UERJ (2017). Disponível em: http://gemaa.iesp.uerj.br/relatorios/relatorio-das-desigualdades-gemaa-no-1/ 


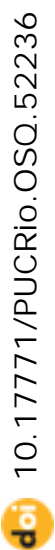

